\title{
KINETICS OF IRON PASSIVATION AND CORROSION IN MOLTEN ALKALI NITRATES*
}

\author{
A. J. Arvia, J. J. Podestá and R. C. V. Piatti \\ Instituto Superior de Investigaciones, División Electroquímica, Facultad de Ciencias Exactas, \\ Universidad Nacional de La Plata, La Plata, Argentina
}

\begin{abstract}
The electrochemical behaviour of iron anodes in molten alkali nitrates has been investigated at temperatures ranging from $c a 240-320^{\circ} \mathrm{C}$. The $E / I$ curves exhibit a potential region where the electrode passivates. Two different oxidized states of the passive iron surface exist. Within definite potential regions, the oxidation of nitrite and iron occurs, the latter being characterized by a Tafel stope of $2 R T / F$. At high positive potentials the breakdown of passivity is observed. Results are interpreted in terms of the stability of possible iron oxides during the electrode reaction. The kinetics of nitrite and nitrate ion oxidation on the passive surface is discussed on the basis of previous work. A comparison between iron passivation and corrosion in molten nitrites and nitrates is made.
\end{abstract}

Résumé-Le comportement des anodes de fer dans des nitrates alcalins fondues est étudié à des temperatures compris entre 240 et $320^{\circ} \mathrm{C}$. Les courbes $E / I$ montrent une région de potentiel où l'électrode se passive. L'oxydation des ions nitrite et fer ont lieu dans des regions definies de potentiel. Cette dernier est caracterisée par une pente de Tafel de $2 R T / F$. Il y a deux différentes état d'oxydation de la surface du fer passivé. A des hautes potentiels anodiques on observe la rupture de la passivité. Les résultats sont interpretés sur la base de la stabilité des possibles oxydes de fer formés pendant la réaction d'électrode. La cinétique de l'oxydation de l'ion nitrite et l'ion nitrate sur la surface passivé est discuté. Une comparaison parmi la passivation et la corrosion du fer dans đes nitrates et nitrites fondues est fait.

Zusammenfassung-Es wurde das elektrochemische Verhalten von Eisenanoden in geschmolzenem Alkalinitrat in einem Temperaturbereich von $240-320^{\circ} \mathrm{C}$ untersucht. Die $E / 1$-Kurven zeigen einen Potentialbereich, in welchem die Elektrode passiviert ist, wobei zwei verschiedene Oxydationszustände der passieven Eisenoberfläche existieren. Innerhalb definierter Potentialbereiche tritt Oxydation der Nitrition und Eisen ein. Bei hohen Anodenpotentialen wird ein Nachlassen der Passivität beobachtet. Die Ergebnisse werden mit der Stabilität möglicher Eisenoxyde interpretiert, die sich während der Elektrodenreaktion bilden. Die Kinetik der Nitrit- und Nitration-oxydation wird auf der Grundlage vorangehender Arbeiten diskutiert. Ferner wird ein Vergleich zwischen Eisenpassivierung und Korrosion in geschmolzenen Nitraten und Nitriten durchgefuhrt.

\section{INTRODUCTION}

KNOWLEDGE of the kinetic behaviour of metals in melts, particularly for iron is rather limited. ${ }^{1}$ Recent work carried out in this laboratory referred to alkali bisulphate $^{2,3}$ and alkali nitrites, ${ }^{4}$ and as part of a systematic investigation, iron-electrode reactions in fused nitrate eutectic are reported.

Reactions of fifteen metals, including iron, in the fused eutectic $\mathrm{LiNO}_{3}-\mathrm{KNO}_{3}$ were studied to establish the main reaction products yielded by decomposition of the melt. ${ }^{5}$ The behaviour of other metal electrodes, such as copper and silver in nitrate melts, has also been studied ${ }^{6-9}$ and some results regarding the behaviour of iron in fused alkali nitrates have been obtained by potentiodynamic polarization technique. ${ }^{10}$ However, the kinetic and mechanisms of the different processes involved were not established, and the present research attempts to establish the possible course of the different processes. The calculation of the potential $/ \mathrm{pO}^{2-}$ diagram for iron in molten nitrate recently made ${ }^{11}$ facilitates interpretation of the reactions involved. Furthermore the possibility of iron passivation in molten alkali nitrates is of interest, because of the low solubility of metal oxides therein.

* Manuscript received 15 September 1970. 
EXPERIMENTAL TECHNIQUE

The cell arrangement, the quality of the iron electrodes and their preparation have been described in previous papers. ${ }^{2,4}$ Sodium nitrate $(45.6 \%$-potassium nitrate $(54.4 \%)$ melts (Carlo Erba) were used as electrolytes under two different conditions: (i) dried at room temperature and (ii) thoroughly dehydrated in the molten state under vacuum for 24-48 h. No particular saturation of the melt was made except that produced by gases generated during the anodic reactions.

The electrochemical processes were studied at temperatures between 240 and $320^{\circ} \mathrm{C}$ by applying galvanostatic and potentiostatic techniques both under steady and non-steady conditions, covering a potential range of $1.5 \mathrm{~V}$. Triangular wave voltammetry was employed following procedures already described in the literature. ${ }^{12}$ Gaseous products were analysed by ir spectrometry. X-ray diffractometry was applied to study the metal surface oxides and the insoluble oxide left in the melt. The latter was also chemically evaluated.

\section{RESULTS}

\section{Oxide-film formation}

The formation of oxide films on the iron electrode was evidenced by X-ray analysis. When the metal is merely immersed in the molten nitrate eutectic, the X-ray diffractograms exhibit the peaks of $\alpha$-iron and that of an iron oxide having the structure of magnetite with a little of $\mathrm{FeO} .{ }^{13}$ When the sample is anodized at $0.025 \mathrm{~V}$ higher than the potential obtained on immersion, the X-ray diffractograms are nearly the same as before, but the intensity ratio of the $\alpha-\mathrm{Fe} / \mathrm{Fe}_{3} \mathrm{O}_{4}(\mathrm{FeO})$ peaks diminishes. Finally, when the sample is anodized at a potential $1.3 \mathrm{~V}$ higher than the initial potential, the peaks corresponding to $\alpha-\mathrm{Fe}$ and $\mathrm{Fe}_{2} \mathrm{O}_{3}$ are observed.

\section{Anodic formation of $\mathrm{Fe}_{2} \mathrm{O}_{3}$}

Various reactions take place at the iron anode in the molten alkali nitrates. At low anode potentials the electrode acquires a passive state. On increasing the potential further, the anodic oxidation of nitrite, usually present in the melt in traces, takes place, the main reaction yielding $\mathrm{NO}_{2}$. At higher anode potentials the formation of nitrogen oxides and the simultaneous oxidation of iron to $\mathrm{Fe}_{2} \mathrm{O}_{3}$. Various other chemical or electrochemical side reactions yield also $\mathrm{N}_{2} \mathrm{O}$ among the reaction products.

The composition of the solid formed at high anodic overvoltages and left as a suspension in the melt was $\mathbf{9 4 . 2}$ per cent $\mathrm{Fe}_{2} \mathrm{O}_{3}$. The remaining 5.8 per cent corresponded to water added to the oxide when it was removed from the melt. X-ray analysis confirmed the structure of $\gamma-\mathrm{Fe}_{2} \mathrm{O}_{3} \cdot \mathrm{H}_{2} \mathrm{O}$ for the solid separated from the melt.

\section{Current/potential curves}

The potentiostatic current/potential curves, as shown in the $E / \log i$ plots defined in terms of the initial geometrical area of the iron sample, exhibit a complex shape (Figs. 1-4). For a description of the initial $E / \log i$ curve obtained with a fresh iron electrode, let us consider a curve recorded by changing the potential upward, at $258^{\circ} \mathrm{C}$. When the anode potential is just a few $\mathrm{mV}$ above the initial potential obtained when the iron sample is immersed in the melt, a sudden increase of current is noticed, 


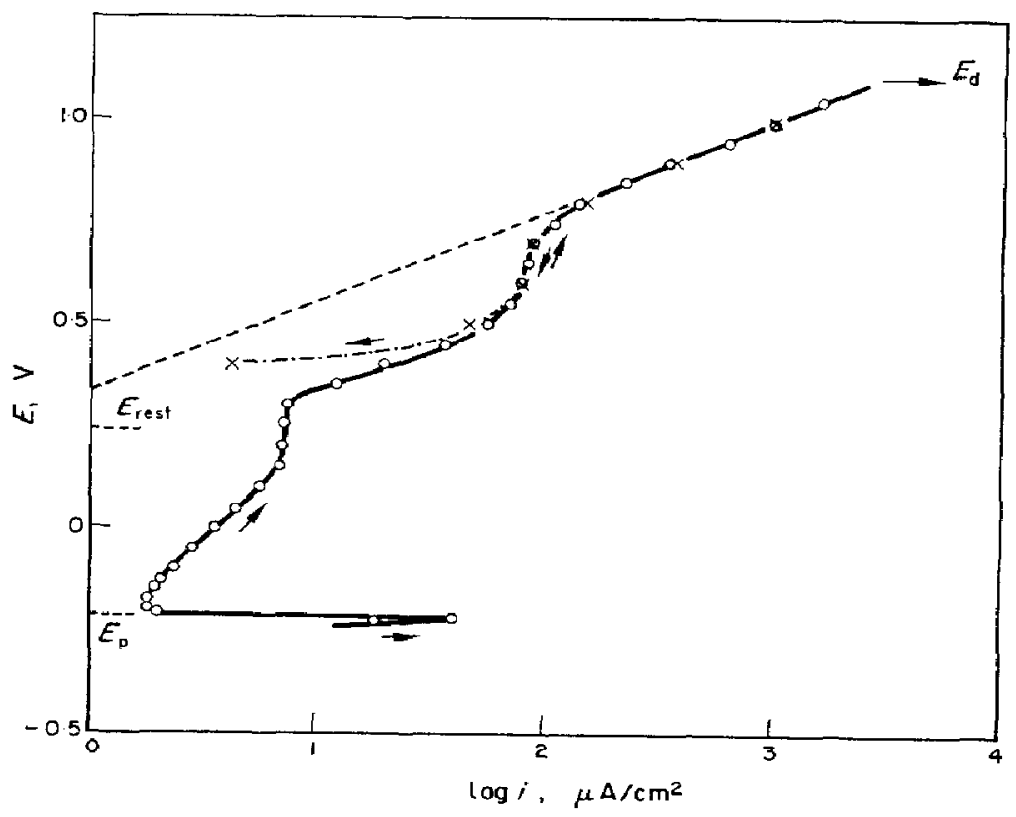

FIo. 1. Semilogarithmic plot of a potentiostatic anodic $E / i$ curve. $263^{\circ} \mathrm{C}$. Dehydrated meit.

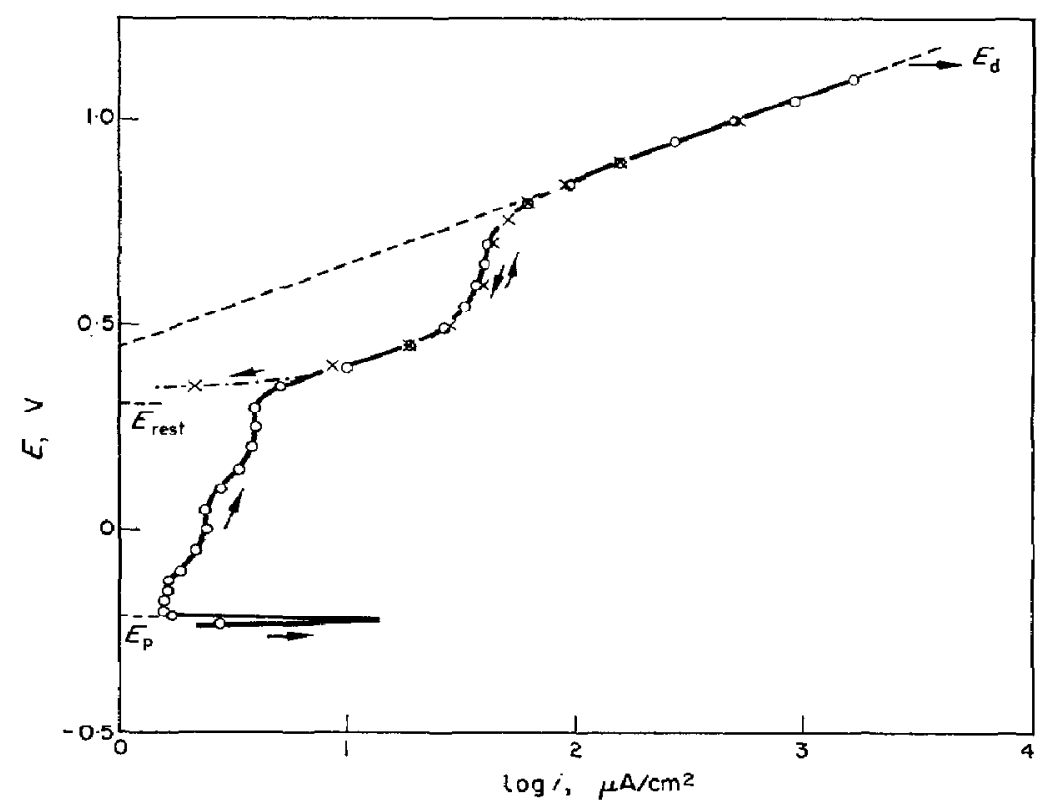

FIo. 2. Semilogarithmic plot of a potentiostatic anodic $E / i$ curve. $309^{\circ} \mathrm{C}$. Dehydrated melt.

and a maximum current density, $i_{\max }$, is reached. This is between 10 and $40 \mu \mathrm{A} / \mathrm{cm}^{2}$, depending on the temperature. Afterwards, a further increase of the anode potential provokes a sharp decrease of current and the onset of a definite passivity. For an approximate $0.1 \mathrm{~V}$ range of anodic potential there is a passivity current, $i_{\min }$, about ten times smaller than the maximum current. On increasing the electrode potential 


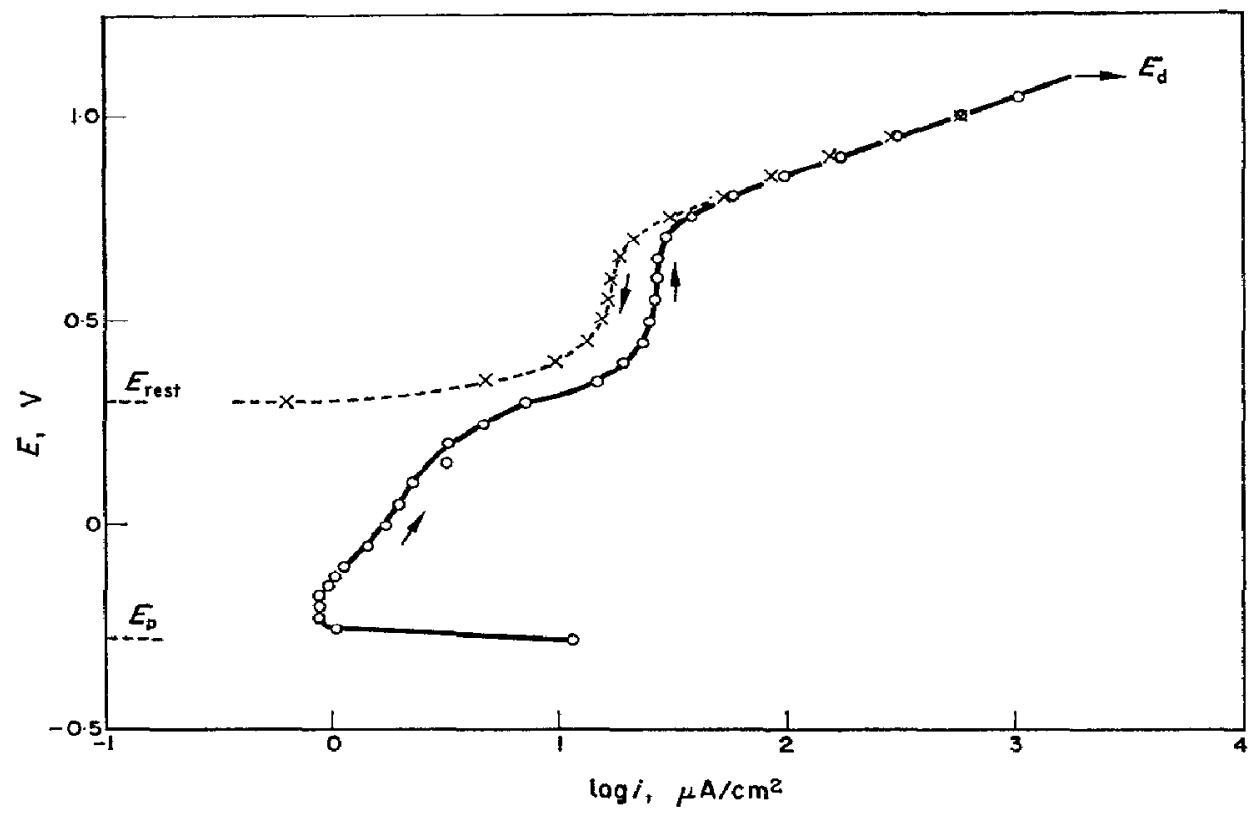

FIG. 3. Semilogarithmic plot of a potentiostatic anodic $E / i$ curve. $243^{\circ} \mathrm{C}$. Partially dehydrated melt.

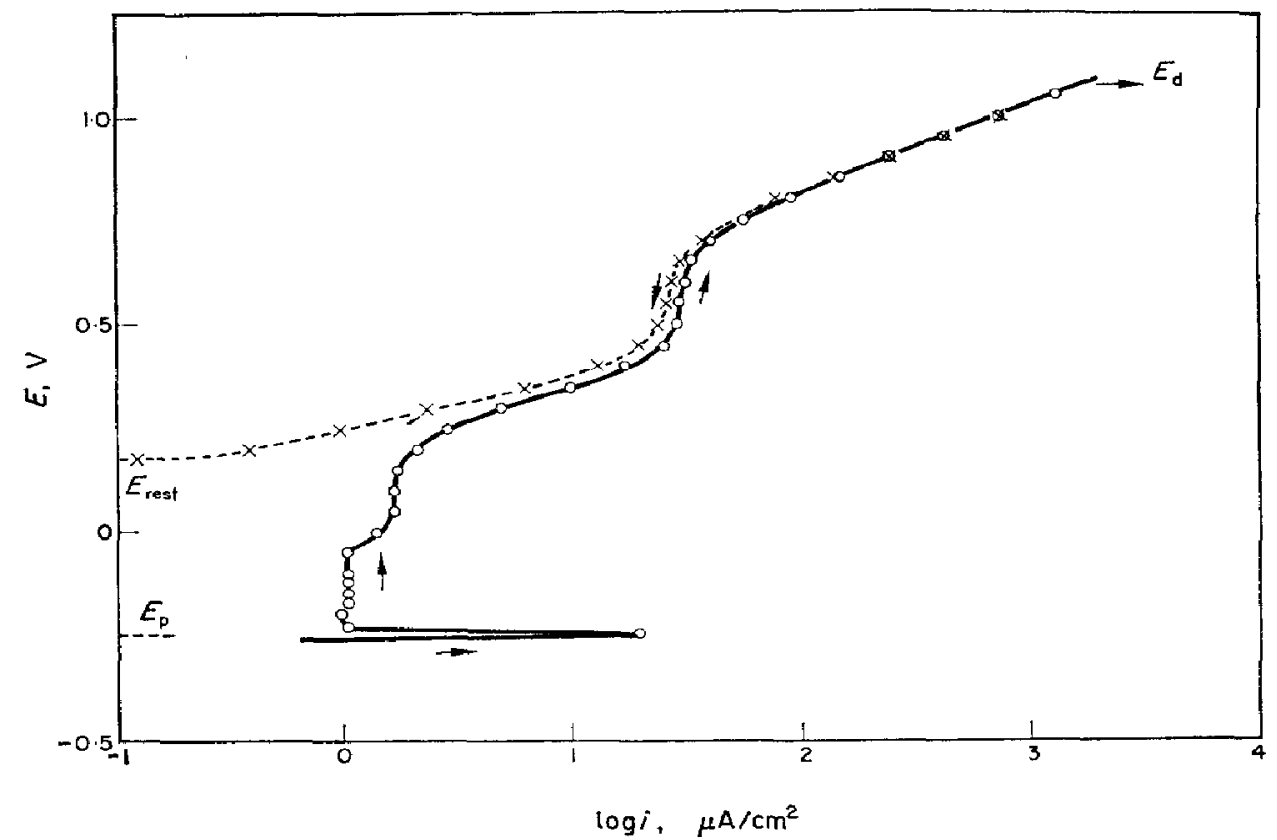

FIG. 4. Semilogarithmic plot of a potentiostatic anodic $E / i$ curve. $271^{\circ} \mathrm{C}$. Partially dehydrated melt.

further, a slow increase of current is observed before the occurrence of the anodic oxidation of nitrite ion. The $E / \log i$ curve in this region is complex in shape and not very reproducible. Beyond a $\Delta E$ of about $0.5 \mathrm{~V}$, nitrite-ion oxidation takes place and a net limiting current is established. The latter is directly proportional to the amount of nitrite present in the melt. This was confirmed by adding known amounts of nitrite to the nitrate eutectic. In this region $\mathrm{NO}_{2}$ is evolved. 
Beyond the limiting current region, the $E / \log i$ curve satisfies a good Tafel line for about one and a half logarithmic decades. Finally when the anode potential reaches $1.15 \mathrm{~V}$, a sudden breakdown of passivity is observed and, at constant potential, the current attains a large value. The features described for the $E / \log i$ characteristics are of the same shape at all temperatures investigated.

If the $E / \log i$ curves are recorded at decreasing potential a different situation is met. Thus, the upper Tafel region is reasonably well reproduced as well as the limiting current region, but the remaining part of the curve is no longer observed as the potential reaches a rather stable value at about $0.450-0.500 \mathrm{~V}$ while the current takes a constant value of the order of $10^{-7} \mathrm{~A} / \mathrm{cm}^{2}$. Under these circumstances if a second $E / \log i$ curve is obtained, it starts from the potential located at $0.450-0.500 \mathrm{~V}$ and its shape reproduces that just reported for the returning curve (Fig. 5).

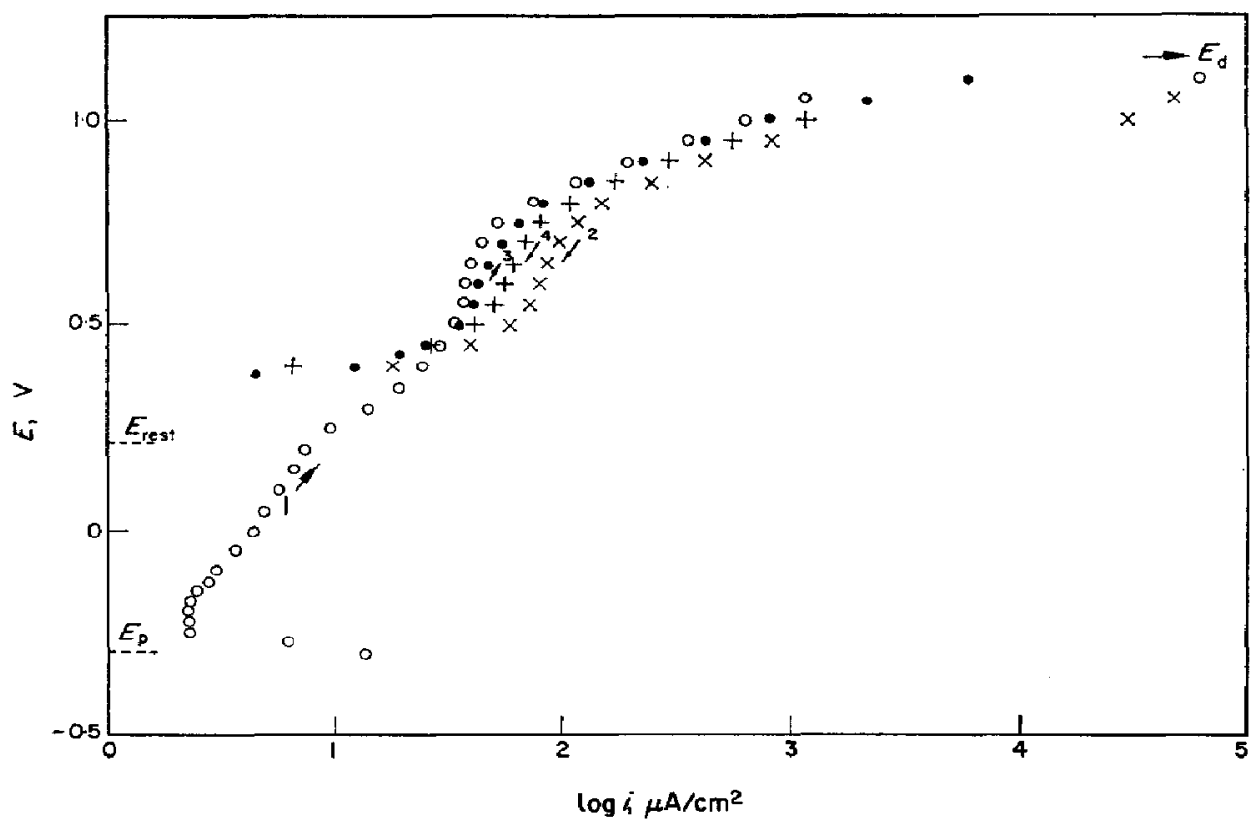

FIo. 5. Semilogarithmic plots of successive anodic potentiostatic runs. $241^{\circ} \mathrm{C}$.

During these experiments it has been observed that the returning $E / \log i$ curve exhibits a limiting cd for nitrite-ion oxidation that may be either smaller or larger than the limiting current of the first run upward. The first situation arises when the anodic run recorded downward starts at potentials within the Tafel line region, and this occurs because of a depletion of nitrite ion in the melt. The second alternative appears when the starting potential is located in the region where the breakdown of passivity takes place, and should be attributed to a significant increase of the anode area because of the massive corrosion then produced.

The slope of the straight-line portion, as shown in the figure, is quite close to $2 \cdot 3(2 R T / F)$ and its extrapolation at the passivation potential, $E_{\mathrm{p}}$, yields a current $\left(i_{0}\right)_{E_{\mathrm{p}}}$ that increases with temperature. The potential $E_{\mathrm{p}}$ was taken as a reference to normalize the reaction rate, since it apparently corresponds to a definite structure of 
the electrode surface, as discussed further on. Table 1 comprises the kinetic parameters obtained from the $E / \log i$ curves. Apparently traces of water are not affecting appreciably neither the foregoing picture of $E / i$ curves nor the magnitude of the kinetic parameters. It must be emphasized that neither $(i)_{\min }$ nor $(i)_{\max }$ nor $E_{\mathrm{p}}$ present any definite dependence on temperature. The only kinetic parameters that actually do depend on temperature are the current $\left(i_{0}\right)_{E_{\mathfrak{p}}}$ and the limiting current, $i_{\mathrm{L}}$, for nitriteion oxidation. The Arrhenius plot for $\left(i_{0}\right)_{E_{p}}$ yields an experimental activation energy equal to $27 \pm 5 \mathrm{kcal} / \mathrm{mole}$ (Fig. 6). The temperature dependence of $i_{\mathrm{L}}$ coincides with already reported figures for the same process. ${ }^{14}$

TAble 1. Kinetic Parameters Derived from $E / \log i$ curves

\begin{tabular}{|c|c|c|c|c|}
\hline${ }^{\text {Temp }} \mathbf{C}$ & $\begin{array}{l}\log i_{\text {min }} \\
\mu \mathrm{A} / \mathrm{cm}^{2}\end{array}$ & $\begin{array}{l}\log i_{\max } \\
\mu \mathrm{A} / \mathrm{cm}^{2}\end{array}$ & $\begin{array}{c}\log i_{\mathrm{L}}, \mathrm{No}_{2}^{-} \\
\mu \mathrm{A} / \mathrm{cm}^{2}\end{array}$ & $E_{\mathrm{p}}$ \\
\hline \multicolumn{5}{|c|}{ Completely dehydrated melt } \\
\hline 243 & 0.58 & $1 \cdot 30$ & $1 \cdot 73$ & 0.275 \\
\hline 258 & $0 \cdot 50$ & $1 \cdot 11$ & 1.65 & 0.200 \\
\hline 263 & 0.20 & $1 \cdot 20$ & 1.60 & 0.210 \\
\hline 271 & $0 \cdot 82$ & 0.50 & 1.80 & 0.200 \\
\hline 298 & $0 \cdot 21$ & $1 \cdot 57$ & $1 \cdot 62$ & $0 \cdot 240$ \\
\hline 309 & 0.26 & $1 \cdot 60$ & 1.90 & 0.220 \\
\hline \multicolumn{5}{|c|}{ Partially dehydrated melt } \\
\hline 241 & $0 \cdot 36$ & $1 \cdot 14$ & $1 \cdot 58$ & 0.300 \\
\hline 243 & -0.07 & 1.05 & $1 \cdot 42$ & 0.278 \\
\hline 271 & 0.21 & $1 \cdot 28$ & 1.46 & 0.240 \\
\hline 278 & 0.88 & $1 \cdot 26$ & $1 \cdot 52$ & 0.278 \\
\hline
\end{tabular}

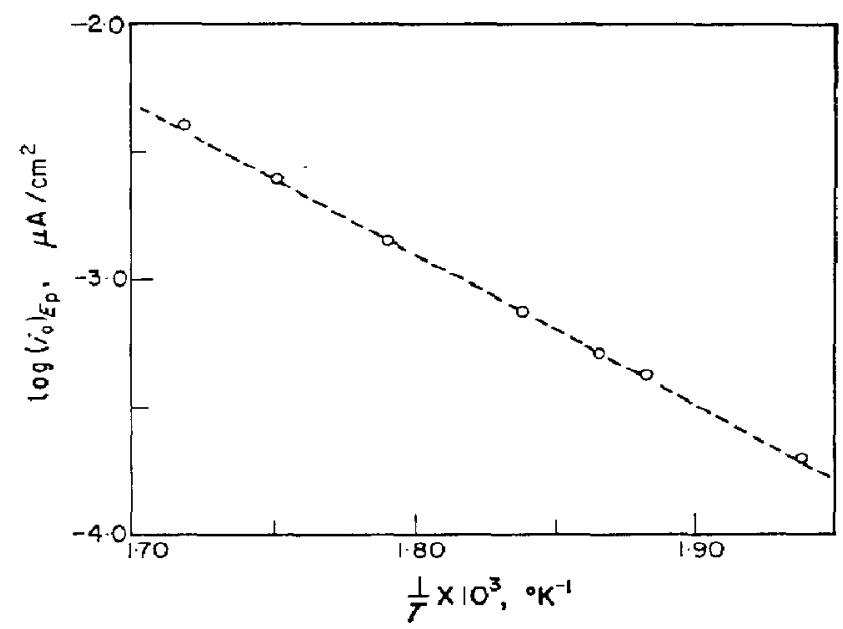

FIG. 6. Arrhenius plot for the current density extrapolated at $E_{\mathrm{p}}$.

\section{Anode-potential decay}

The anode-potential decays are depicted as overvoltage/log(time) plots in Fig. 7, the overvoltage being referred to the passivation potential. The plots are rather complex as they should correspond to the $E / \log i$ curve previously described. However, in the range of potential between 0.85 and $1.20 \mathrm{~V}$, they exhibit the shape predicted for 


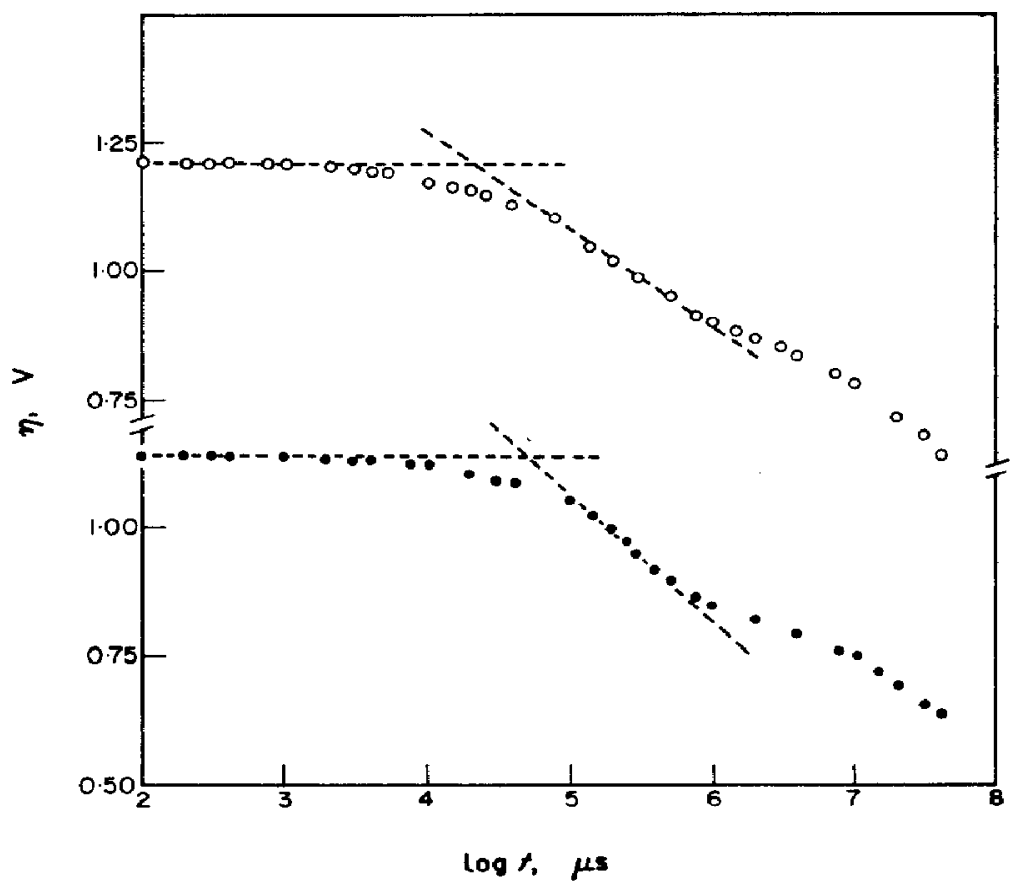

Fra. 7. Semilogarithmic plots of anodic overvoltage decay. $271^{\circ} \mathrm{C}$.

a rather simple electrode process. This potential range coincides precisely with the Tafel line region already represented in the $E / \log i$ curves. Therefore, only from that portion of the overvoltage/log(time) plot can reliable kinetic parameters be in principle derived. The decay slope, $b_{\mathrm{d}}$, and the apparent electrode differential capacitance, $C_{\mathrm{a}}$, evaluated from the $t^{\prime}$ times, defined by the decay slope at the potential of current interruption, are assembled in Table 2. The decay slope is close to $2 \cdot 3(2 R T / F) \mathrm{V}$,

TABle 2. Kinetic Parameters Derived FROM DECAY CURVEs, $271^{\circ} \mathrm{C}$

\begin{tabular}{ccccc}
\hline $\begin{array}{c}E-E_{\mathrm{p}} \\
\mathrm{V}\end{array}$ & $\begin{array}{c}i \\
\mathrm{~A} / \mathrm{cm}^{2}\end{array}$ & $\begin{array}{c}b_{\mathrm{d}} \\
\mathrm{V}\end{array}$ & $\begin{array}{c}\boldsymbol{t}^{\prime} \\
\mathrm{s}\end{array}$ & $\begin{array}{c}C_{\mathrm{a}} \\
\mu \mathrm{F} / \mathrm{cm}^{2}\end{array}$ \\
\hline 1.07 & 101 & 0.280 & $6.9 \times 10^{-2}$ & 58 \\
1.14 & 245 & 0.235 & $5.0 \times 10^{-2}$ & 117 \\
1.21 & 508 & 0.200 & $2.0 \times 10^{-2}$ & 117 \\
\hline
\end{tabular}

a figure which agrees with that derived from the $E / \log i$ plot. The apparent electrode differential capacitances seem to attain a constant value at high anodic overvoltages. Unfortunately, due to the complexity of the electrode reaction at lower overvoltages, no further conclusions can be safely drawn from the decay slopes.

\section{Triangular wave voltammetry}

Voltammetric $E / I$ curves were recorded after repetitive cycles at potential sweeps from $0 \cdot 157-7 \cdot 80 \mathrm{~V} / \mathrm{s}$. At lower sweep rates, covering the range of anode potential from $0-1.0 \mathrm{~V}$, the $E / I$ display shows one anodic current peak and one cathodic current 
peak separated by $0.2 \mathrm{~V}$, as shown in Fig. 8a. The former corresponds to the potential region preceding net $\mathrm{Fe}_{2} \mathrm{O}_{3}$ formation, and the latter is related to reduction of products, probably $\mathrm{NO}_{2}$, yielded during the anodic cycle. Figure 8 a shows a typical $E / I$ curve of a reaction occurring on a passivated electrode. If the sweep potential reaches the cathodic region (Fig. 8b), then two new current peaks are observed in addition to the anodic already-mentioned current peak. The cathodic current peak
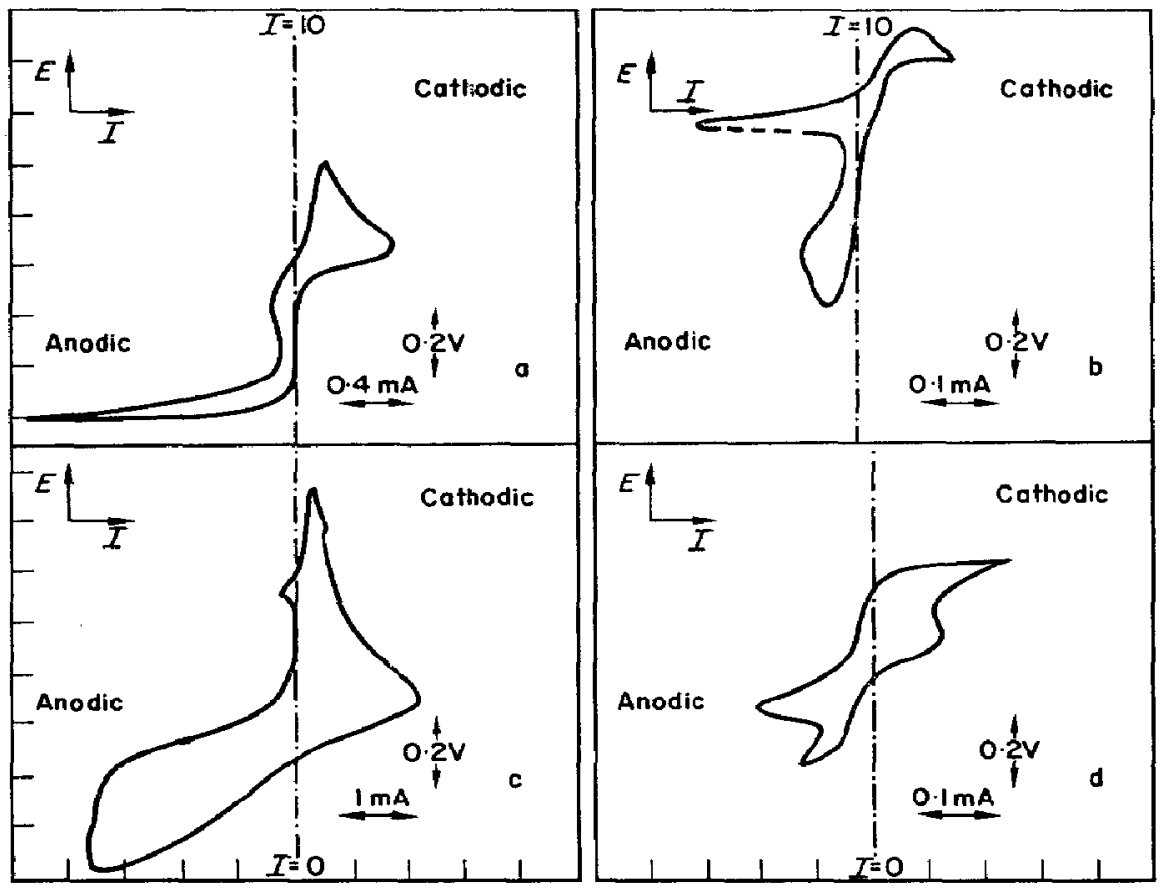

Fig. 8. Voltammetric $E / I$ curves at $258^{\circ} \mathrm{C}$. Dehydrated melt.

seems to be related to the destruction of the oxide film, while the anodic current peak corresponds to the reformation of the passive film. If the first is related to the passivity potential, the anodic current peak appearing at higher anodic potentials should be assigned to the initiation of $\mathrm{Fe}_{2} \mathrm{O}_{3}$ formation or nitrate-ion discharge. At low sweep rates, the $E / I$ curves for a passive electrode exhibit the already mentioned features, and on expanding the scale adequately, the $E / I$ curve presents a shoulder at the beginning of the anodic peak assigned to nitrate ion (Fig. 8c). That shoulder belongs to nitrite-ion discharge, which exists as an impurity in the molten nitrate. Its potential, at the lower sweep rates, is close to the potential of the cathodic current maximum mentioned above. The identification of the nitrite peak was established by adding nitrite to the nitrate eutectic and observing the corresponding current-peak increase. The separation of the peaks related to nitrite-ion discharge, and $\mathrm{NO}_{2}$ reduction is achieved at the highest sweep rate, as shown in Fig. 8d. If the nitrite electrode under these circumstances behaves irreversibly, the predicted shift of the anodic and cathodic current maxima at the sweep rates indicated in Fig. $8 \mathrm{c}$ and Fig. 8d, should be close to $0.3 \mathrm{~V}$, as indeed found. 


\section{DISCUSSION}

There is good experimental evidence that iron passivates when it comes in contact with the alkali nitrate eutectic, and that passivity is caused by a film which has initially a predominantly magnetite structure. The first potentiostatic $E / I$ curve obtained with a new iron electrode exhibits the typical passivity phenomena already reported for iron electrodes in other melts. ${ }^{2,4}$ After the electrode acquires the passive state, on increasing the anode potential a further oxidation of the passive film occurs and nearly simultaneously the discharge of nitrite ions takes place. The latter process involves a net convective-diffusion limiting current, the magnitude of which depends on the amount of nitrite present in the melt. At still higher potentials, the anodic oxidation reaction is characterized by a Tafel line whose slope lies close to $2 R T / F$. At a further increase of the anode potential a clear breakdown of passivity is established; the current increases abruptly when the anode potential increases by just a few $\mathrm{mV}$. These features of the first $E / I$ curve contrast with those exhibited when the $E / I$ curve is retraced backward by decreasing the anode potential, or by recording $E / I$ curves repeatedly after the electrode is passivated. In all these cases the starting potential is more positive and the passivity region is not observed.

\section{Thermodynamic considerations}

Before discussing the possible reaction pathways for the electrode processes involved within each potential region, let us first try to establish the thermodynamic limits of stability of the iron electrode in alkali nitrate melts, on the basis of the potential/: $\mathrm{pO}^{2-}$ diagram recently calculated. ${ }^{11}$ The concentration of oxide ions in the melt is estimated from the equilibrium ${ }^{15}$

$$
\mathrm{NO}_{3}^{-}=\mathrm{NO}_{2}{ }^{+}+\mathrm{O}^{2-},
$$

of which the equilibrium constant at various temperatures is known. ${ }^{15}$ The oxide ion concentration at $600^{\circ} \mathrm{K}$ is estimated as $10^{-13}$ mole/l. Besides, the following additional equilibria must be considered,

$$
\begin{aligned}
\mathrm{Fe}^{2+}+2 \mathrm{e} & \rightleftarrows \mathrm{Fe} \\
\mathrm{Fe}^{3+}+3 \mathrm{e} & \rightleftarrows \mathrm{Fe} \\
\mathrm{FeO}+2 \mathrm{e} & \rightleftarrows \mathrm{Fe}+\mathrm{O}^{2-} \\
\mathrm{Fe}_{3} \mathrm{O}_{4}+2 \mathrm{e} & \rightleftarrows 3 \mathrm{FeO}+\mathrm{O}^{2-} \\
\mathrm{Fe}_{3} \mathrm{O}_{4}+2 \mathrm{e} & \rightleftarrows 3 \mathrm{Fe}^{2+}+4 \mathrm{O}^{2-} \\
3 \mathrm{Fe}_{2} \mathrm{O}_{3}+2 \mathrm{e} & \rightleftarrows 2 \mathrm{Fe}_{3} \mathrm{O}_{4}+\mathrm{O}^{2-} \\
\mathrm{Fe}_{2} \mathrm{O}_{3}+2 \mathrm{e} & \rightleftarrows 2 \mathrm{Fe}^{2+}+3 \mathrm{O}^{2-} \\
\mathrm{FeO} & \rightleftarrows \mathrm{Fe}^{2+}+\mathrm{O}^{2-} \\
\mathrm{Fe}_{2} \mathrm{O}_{3} & \rightleftarrows 2 \mathrm{Fe}^{3+}+3 \mathrm{O}^{2-},
\end{aligned}
$$

for which the Nernst equations at $600^{\circ} \mathrm{K}$ have been reported elsewhere, ${ }^{11}$ indicating that any iron dissolution reaction as $\mathrm{Fe}^{2+}$ or $\mathrm{Fe}^{3+}$ soluble in this melt should be discarded, since initially magnetite formation is most favoured in the present circumstances.

Furthermore, an important limit of thermodynamic stability in the $E / \mathrm{pO}^{2-}$ diagram is set by the equilibrium

$$
\frac{1}{2} \mathrm{O}_{2}+2 \mathrm{e} \rightleftarrows \mathrm{O}^{2-} \text {, }
$$


for which the Nernst equation, at $600^{\circ} \mathrm{K}$, referred to the standard nitrate electrode, is

$$
E_{\mathrm{XI}}=-1 \cdot 758+\frac{R T}{z F} \ln \frac{p_{\mathrm{O}_{2}}^{1 / 2}}{a_{\mathrm{O}^{2-}}} .
$$

Equilibrium (XI) corresponds to the oxygen/oxide electrode in the melt.

These equilibria define the different potential regions where certain processes are thermodynamically possible, and a good idea about those limits can be obtained through the potential difference, derived from the Nernst equations at a constant oxide-ion activity, between equilibria (IV) or (V) and (VII) and (IV) or (V) and (XI). At $600^{\circ} \mathrm{K}$ the first difference is $0.325 \pm 0.050 \mathrm{~V}$ and the second is $1.220 \pm 0.060 \mathrm{~V}$. The first figure can be compared with that deduced as the potential difference between the passivation potential, $E_{\mathrm{p}}$, and the rest potential, $E_{\mathrm{rest}}$, obtained from the returning $E / I$ curve. The second figure, on the other hand, may be related to the difference between the passivation potential, $E_{\mathrm{p}}$, and the potential where breakdown occurs, $E_{\mathrm{d}}$. Figures derived from the $E / I$ curves are assembled in Table 3. The comparisons indicate a fairly reasonable agreement of the corresponding differences. Therefore, the $E / I$ curves comprise at least three well defined potential regions to be independently analysed. The first implies the initial oxide formation on the iron surface; the second is related to the oxidation of nitrite and $\mathrm{Fe}_{2} \mathrm{O}_{3}$ formation and the third refers to tha massive electrochemical oxidation of the iron electrode.

Table 3. Characteristic potentials from $E / \log i$ curves

\begin{tabular}{|c|c|c|}
\hline$\underset{{ }^{\circ} \mathrm{C}}{\mathrm{Temp}}$ & $E_{\mathrm{rest}}-E_{\mathrm{p}}$ & $E_{\mathrm{d}}-E_{\mathrm{v}}$ \\
\hline \multicolumn{3}{|c|}{ Completely dehydrated melt } \\
\hline 243 & 0.722 & $1 \cdot 292$ \\
\hline 258 & 0.550 & $1 \cdot 350$ \\
\hline 263 & 0.520 & $1 \cdot 310$ \\
\hline 271 & 0.560 & $1 \cdot 300$ \\
\hline 286 & 0.550 & $1 \cdot 310$ \\
\hline 298 & 0.450 & $1 \cdot 310$ \\
\hline 309 & 0.450 & $1 \cdot 315$ \\
\hline \multicolumn{3}{|c|}{ Partially dehydrated melt } \\
\hline 241 & 0.650 & $1 \cdot 350$ \\
\hline 243 & 0.575 & $1 \cdot 325$ \\
\hline 261 & 0.570 & $1 \cdot 320$ \\
\hline 271 & 0.425 & $1 \cdot 300$ \\
\hline 278 & 0.550 & $1 \cdot 320$ \\
\hline 299 & 0.530 & $1 \cdot 320$ \\
\hline 320 & 0.565 & $1 \cdot 300$ \\
\hline
\end{tabular}

The passive state of iron in molten nitrates

Iron-oxide film formation should occur preferentially according to the over-all reactions represented by (IV) to (VIII), and simultaneously nitrogen oxides are yielded either by reduction of the nitrate or nitronium ions, or any equivalent species that exists in the melt.

The film producing passivity requires a thickness of a few layers, as deduced from the area of the corresponding current peak obtained at different sweep rates. The predominant structure of the thicker passivating films obtained at low anodic potential, as revealed by $\mathrm{X}$-ray diffractograms, corresponds to magnetite with traces of FeO. ${ }^{13}$ 
At higher anode potentials the oxide film approaches the $\mathrm{Fe}_{2} \mathrm{O}_{3}$ structure, as also shown by $\mathrm{X}$-ray diffractograms. No definite potential region can be assigned to the composition change of the film which apparently occurs at potentials in between the passivity potential and the breakdown potential. The rest potential, after electrolysing the melt at high anodic potentials, eventually approaches (after a long time) the value corresponding to equilibrium VII. Any further continuous use of the electrode as anode involves as starting surface a predominantly $\mathrm{Fe}_{2} \mathrm{O}_{3}$ /iron electrode.

\section{The anodic discharge of $\mathrm{NO}_{2}^{-}$and $\mathrm{Fe}_{2} \mathrm{O}_{3}$ formation}

Once the iron electrode is passivated, nitrite-ion oxidation first takes place, according to the over-all reaction

$$
\mathrm{NO}_{2}^{-} \rightarrow \mathrm{NO}_{2}+\mathrm{e}
$$

The formation of $\mathrm{NO}_{2}$ may also contribute to the oxidation of the passivated film to $\mathrm{Fe}_{2} \mathrm{O}_{3}$. The discharge of nitrite ion on the passivated iron surface is under these circumstances mainly a convective-diffusion controlled process, the steady $E / i$ curves being characterized by a net limiting current and the voltammetric $E / I$ curves by two current peaks that occur at nearly the same potential if low sweep rates of potential are employed.

Gaseous $\mathrm{NO}_{2}$ in the presence of nitrite ions undergoes the reaction

$$
\mathrm{NO}_{2}+\mathrm{NO}_{2}^{-}=\mathrm{NO}_{3}^{-}+\mathrm{NO} \text {. }
$$

A further increase of anode potential produces $\mathrm{Fe}_{2} \mathrm{O}_{3}$ formation. The kinetics of this reaction is not possible at present to be interpreted in terms of a reaction pathway. It comprises a Tafel slope equal to $2 R T / F$ which suggests that an initial one electron transfer step is rate determining.

$\mathrm{NO}_{2}$ and $\mathrm{NO}$ participate in the oxidation of the base metal to ferric oxide, the former being partially reduced to $\mathrm{N}_{2} \mathrm{O}$, as indicated by the composition of the gaseous products. The existence of $\mathrm{NO}$ as a stable product is prevented if oxygen atoms are formed as reaction intermediates.

\section{The breakdown of passivity}

When the anode potential exceeds $1 \cdot 3 \mathrm{~V}$ with respect to the passivation potential, passivation abruptly disappears. The potential for the occurrence of this process is close to the thermodynamic potential of the oxygen/oxide-ion electrode. The latter in molten systems containing molten oxyanions and in oxide melts at high temperature ${ }^{\mathbf{1 4}}$ constitutes a reversible electrode represented by reaction (XI), which has been the subject of previous research.1,16

At this high anode potential, the source for oxide ions may well be located either in the ferric oxide layer or in the melt, where they are in equilibrium with nitrate and nitronium ions, as indicated by reaction (I). If the oxide ion discharge takes place in the film, the ferric ion, which is thermodynamically unstable in the molten nitrate, decomposes into $\mathrm{Fe}_{2} \mathrm{O}_{3}$ and nitrogen oxides. Consequently the oxide layer breaks down and massive ferric oxide formation results. Iron dissolution is enormously accelerated as the passive oxide film no longer protects the metal surface. Therefore, if reaction (XI) is a fast process, the rate of the over-all reaction appears as potentialindependent, the kinetics probably being governed by a chemical reaction. 


\section{Comparison of iron electrode behaviour in molten nitrates and nitrites}

Iron electrodes in both melts definitely acquire a passive state and any electrochemical oxidation occurs on the passive iron clectrodes. However, some differences are established for the behaviour of iron in the two melts. Thus, although initially the passivation process predominantly involves an iron oxide of the magnetite structure for both nitrite and nitrate melts, only for the latter does the oxidation to ferric oxide proceed. This difference is also reflected in the composition of gaseous products yielded by both anodic processes. In the nitrite melt $\mathrm{NO}$ and $\mathrm{NO}_{2}$ are the main gaseous products, whereas for the nitrate melt $\mathrm{NO}_{2}$ and $\mathrm{N}_{2} \mathrm{O}$ appear as the predominant products.

Another clear difference exists at high anode potentials where iron dissolution in the nitrate eutectic becomes practically potential-independent. This region has not been observed for the nitrite melt, perhaps because the region corresponding to the oxide/oxygen electrode is not reached.

Acknowledgement-The authors thank the Consejo Nacional de Investigaciones Cientificas y Técnicas for financial support. J. J. P. acted as a part-time researcher of the Departamento de Ingeniería Química de la Universidad Nacional de La Plata.

\section{REFERENCES}

1. Yu. K. Delimarsku and B. F. Markov, Electrochemistry of Fused Salts. Sigma Press, Washington (1961).

2. R. Casino, J. J. Podestá and A. J. ARviA, An. Asoc. quim. argent. 58, 107 (1970).

3. R. Casino, J. J. PodestÁ and A. J. Arvta, Electrochim. Acta, 16, 121 (1971).

4. A. J. ARví, J. J. PodestÁ and R. C. V. PIATT, Electrochim. Acta, 16, 1797 (1971).

5. B. J. Brough and D. H. KerRIDGe, Inorg. Chem. 4, 1353 (1965).

6. D. Buttinelli, G. De Gregorio and G. Signorelli, Ric. Sci. 31,127 (1961).

7. H. Shimotake and J. C. Hesson, Adv. Chem. Ser. No. 64, p. 156. Am. chem. Soc. (1967).

8. A. Conte, Electrochim. Acta 11, 1579 (1966).

9. A. CONTE and M. D. InGRAM, Electrochim. Acta 13, 1551 (1968).

10. A. Conte and S. Casadio, Ric. Sci. 36, 433 (1966).

11. S. L. Marchiano and A. J. Arvía Electrochim. Acta 17, 25 (1972).

12. R. N. ADAms, Electrochemistry at Solid Electrodes. Dekker, New York (1969).

13. W. Parrish and M. MACK, Data for X-Ray Analysis. A.S.T.M. Special Technical Publication 48-I, Philadelphia (1960).

14. A. J. Arvia, A. J. Calandra and M. E. Martins, Electrochim. Acta 11, 963 (1966).

15. R. N. Kunst and F. R. Duke, J. Am. Chem. Soc. 85, 3338 (1963).

16. D. J. G. Ives and G. JANZ, Reference Electrodes, Theory and Practice, p. 577. Academic Press, New York and London (1961). 